\title{
Reasoning by Consequences: Applying different Argumentation Structures to the Analysis of Consequentialist Reasoning in Judicial Decisions
}

\author{
Razonamiento por consecuencias: aplicando diferentes \\ estructuras de argumentación al análisis del razonamiento \\ consecuencialista en las decisiones judiciales
}

\author{
Flavia Carbonell \\ Faculty of Law, Alberto Hurtado University, Santiago, Chile \\ fcarbone@uahurtado.cl
}

Received: 27-07-2011 Accepted: 19-11-2011

\begin{abstract}
Out of the different theoretical proposals involved in setting directives and constructing models for rationally controlling judicial decisions, some proposals pay particular attention to consequentialist arguments. This paper analyses the diverse approaches to consequentialist arguments given by MacCormick's theory, Wróblewski's theory and Feteris's pragma-dialectical theory, with the purpose of, firstly, comparing, at theoretical level, the differences and nuances of emphasis on what the problematic nodes are when arguing by consequences is at stake. For testing the scope of the proposals, the paper will, secondly, use the selected theories in a study of the consequentialist arguments used by a ruling of the Chilean Constitutional Court. The theoretical comparison, together with the outcomes to which the analysis of judicial argumentation leads, will shed light on the capacity and efficacy of these tools in guiding the rational construction and evaluation of judicial reasoning. Lastly, the paper will stress the role of modelling or of making precise the criteria and indicators for the correctness of legal argumentation.
\end{abstract}

Keywords: Consequentialist arguments, legal argumentation, judicial decisions.

Resumen: Fuera de las diferentes propuestas envueltas en la fijación de directivas y construcción de modelos para el control racional de las decisiones judiciales, algunas de ellas ponen atención particular en los argumentos consecuencialista. Este trabajo analiza los diversos acercamientos a los argumentos consecuencialista dados por la teoría de MacCormick, la teoría de Wróblewski y la teoría pragma-dialéctica de Fe- 
teris, con el propósito, primero, de comparar a nivel teórico las diferencias y matices de los énfasis respecto de cuáles son los nudos problemáticos cuando la argumentación por consecuencia está bajo escrutinio. Para testear el alcance de las propuestas, el trabajo usará, en segundo término, las teorías seleccionadas en un estudio de los argumentos consecuencialista usados por la Corte Constitucional de Chile. La comparación teórica, junto con los productos que el análisis arroja, echará luz sobre la capacidad y eficacia de estas herramientas en guiar la construcción y evaluación racional del razonamiento judicial. Por último, el trabajo enfatizará el rol del modelamiento de los criterios e indicadores para la corrección de la argumentación legal.

Palabras clave: Argumentos consecuencialista, argumentación legal, decisiones judiciales.

\section{Introduction}

Theories of legal argumentation, as many scholars point out, arise in legal theory as an echo of the argumentative turn in philosophy of language and as a middle way between the idea of a mechanistic judge and an arbitrary judge with absolute discretion. These theories propose a diverse range of criteria both for guaranteeing rationality and reasonableness of legal decisions -especially judicial ones- and for enabling intersubjective scrutiny or public control on the process of adjudication (García Amado, 1986, pp. 152-154).

One of the arguments that have received some attention by theorists is the argument from consequences, also called pragmatic argument or consequentialist reasoning. This argument is generally used in the context of judicial hard cases -that is, when problems of interpretation, relevance, classification or proof arise, according to MacCormick's classification $^{1}$ - where judges have to justify their decisions using different types of argument and where the justification efforts are directed at reinforcing the chain of arguments. The theoretical proposals concerned with the argument from consequences consider diverse elements and variables that are necessary for assuring the theory's correct, strong and sound construction and its proper use.

Even if consequentialist reasoning is not a new technique in legal ar-

${ }^{1}$ The first two of these problems have to do with the major premise (law), and the others with the minor premise (facts). See MacCormick (1997, pp. 65-72; pp. 87-97). 
gumentation, its use in justifying legal decisions, particularly judicial decisions, is not exempt from criticisms, nor has it had a homogenous reception within legal theorist and judicial practice. The criticisms refer to different problematic aspects of consequentialist arguments, such as insufficiently backing the prediction of future consequences, the extension of the consequences to be considered, proof of the causal relation between an act and its foreseen consequences, the parameters to evaluate or assess consequences against other values, interest or goods, and the question for what or for whom are the consequences favourable or unfavourable, among others. In the legal sphere we can add questioning about the legitimacy of judges incorporating extra-legal consequences as reasons for deciding in one way or another and problems of excessive judicial discretion and weak accountability mechanisms when these sorts of arguments are at stake. ${ }^{2}$ This paper will not discuss all of these issues. ${ }^{3}$ Thus, i.e., I will not develop at large the issue of whether judges do, can, must or should not use consequentialist extra-legal argumentation. Instead, the starting-point is that since judges use the argument from consequences to justify their decisions, it would be relevant to identify which are the theoretical tools that help them to make a better use of this argument. With this as the premise, I will focus specially on the different parameters proposed by legal theorists to evaluate the use of the argument from consequences, pointing out the problems derived from these proposals and offering a possible solution to them or at least a way of mitigating them.

The aim of this paper is to perform a preliminary comparison among the theoretical approaches to consequentialist reasoning developed by three scholars -MacCormick, Wróblewski and Feteris- bearing in mind the common purpose of legal argumentation theories in order to provide tools for constructing good or correct arguments, or indicators for improving, modelling or guiding the practice. The comparison will be done considering a ruling of the Chilean Constitutional Court. This case-study will

${ }^{2}$ Dworkin tackles this problem by saying that consequences-based reasoning denies past judicial and political decisions and displaces the conception of welfare of the community by the judge's own conception. Dworkin (1986, p. 101; p. 152).

${ }^{3}$ For a panorama of the debates in legal scholarship on the argument from consequences see Bengoetxea (1993); for an introduction to the philosophical consequentialism - nonconsequentialism debate, see Scheffler (1998), Sinnot-Armstrong (2006), Slote (1992). 
be useful to identify strengths and weaknesses of the three theoretical proposals.

The structure of this contribution will be the following. I will first consider very briefly two aspects of consequentialist arguments (a concept and a distinction), and I will highlight the central points of each of the theoretical proposals. Secondly, I will apply these proposals to the evaluation of some consequentialist arguments of a recent decision of the Chilean Constitutional Court. The final section will offer some conclusive remarks.

\section{Theories on consequentialist reasoning}

In this section, I will explain the concept of the argument from consequences and I will outline a distinction that is relevant when applying this argument to legal reasoning. Second, I will briefly describe the way in which three scholars that have delved into the analysis of the argument from consequences have tackled the problems and elements involved in the argument's use.

By "consequentialist argument" I refer to an argument that takes into account the positive or negative consequences that a particular legal decision may produce as a reason to support or reject that decision. ${ }^{4}$ From this definition, it is relevant to emphasise that, on the one hand, consequences are brought forward as reasons to support decisions or, most of the time, to reject decisions with unacceptable, harmful or unfavourable effects, either for the legal system or for the society, i.e., consequences are a factor or a reason for making a decision; ${ }^{5}$ however, on the other hand, those consequences that act as reasons for the decision are future and hypothetical ones, that is, they are only foreseen or foreseeable. In what follows, I will

${ }^{4}$ The argument from consequences has been generally conceptualized as "the argument for accepting the truth (or falsity) of a proposition citing the consequences of accepting that proposition (or of not accepting it)". Walton (1999, p. 252). This same argument, under the name of "pragmatic argument", is defined by Perelman as "the one that enables to evaluate an act or event in accordance with its favourable or unfavourable consequences". Perelman and Olbrechts-Tyteca (2000, p. 409).

${ }^{5}$ MacCormick differentiates between the result of a decision -understood as the legal effects that must be applied to a case when the factual and normative requirements prescribed by the rule are met- and its consequences as a factor for deciding (1983, p. 246). 
be using as interchangeable the expressions "consequentialist reasoning," "argument from consequences" and "argument referring consequences." I will also circumscribe the analysis of judicial decisions as a paradigmatic case of legal decisions.

Concerning the argument from consequences in the legal sphere, it is interesting to distinguish -following the suggestions of several scholars ${ }^{6}-$ between two types of consequences: legal and extra-legal ones ${ }^{7}$. Legal consequences are the effects of a decision inside the legal system or the possible legal implications of a decision internally (Bengoetxea, 1993a, p. 256). In this sense, the use of the argument from legal consequences looks for consistency and coherence of a ruling with the Constitution and the rest of the norms of the legal system and, at the same time, tries to avoid legal gaps and deregulation. Thus, consequentialist argumentation appears frequently together with arguments based on coherence, and it is used mainly to dismiss solutions that produce effects that are incoherent with the legal system as a whole or with the specific principles of a branch of law (Bengoetxea, 1993b, p. 48). Some examples of the use of the argument of legal consequences are: to avoid legal uncertainty, to avoid normative gaps, to avoid empting the content of a legal competence, to avoid injuries to the rights of third parties in good faith, and to reject generic appeals to future damages. $^{8}$

On the other hand, extra-legal consequences are all those repercussions that a judicial decision may have in the extra-legal social reality or outside

${ }^{6}$ Bengoetxea, following MacCormick, distinguishes, in my view, between these two types of consequentialist arguments, even when not with this terminology: a) those consequences that refer to the possible internal juridical implications of a legal decision, that is, within Law as a legal system; and b) those consequences that might follow a judicial decision in Law that refer to the results or repercussions (in behavioural terms), for example, consequences in the economy or in Law as a social system or in other systems. Bengoetxea (1993a, p. 256). See also the distinction between juridical and behavioural consequences in MacCormick (1983, p. 251). An analogy could also be made with the categories "normative" and "factual" consequences within the trilogy proposed by Wróblewski (1984, p. 151).

${ }^{7}$ Scholars have also elaborated other classifications that, although interesting, will not be developed here: causal and remote, favourable and unfavourable, foreseeable and certain, particular and systemic. See, for example, Perelman and Olbrechts-Tyteca (2000, p. 414); Gottlieb (1968, p. 76); MacCormick (1997, p. 150).

${ }^{8}$ These type arguments come from an analysis of a set of rulings of the Spanish Constitutional Court that I did a couple of years ago. Following the order of the text, these rulings are: STC $45 / 1989$, de $20^{\text {th }}$ February; STC $195 / 1998,1^{\text {st }}$ October; STC $75 / 1984,27^{\text {th }}$ June; STC $37 / 1981,16^{\text {th }}$ November; STC $178 / 2004,21^{\text {st }}$ October; STC $184 / 2004,2^{\text {nd }}$ November. 
the legal system. Like the argument from legal consequences, an argument referring to extra-legal consequences is commonly a negative one. That is, the argument is incorporated in judicial reasoning to justify the rejection of a competing decision because of that decision's unfavourable or undesirable consequences. Some examples of extra-legal consequences are: the economic consequences, for the local government, of reviewing or annulling a town-planning administrative permission; the impact in the public funds derived from the duty of the state to return taxes paid on behalf of a statute declared void; the variations produce by a decision on the economic and financial state policy; the negative political effect of the failure to comply with an international duty; the changes in the logic of the democratic system; the social consequences produced by the introduction of modifications in the labour policy. ${ }^{9}$

The relevance of distinguishing among these two types of consequences is twofold. Firstly, the argument referring legal consequences is less controversial than the argument referring to extra-legal consequences. This is so since legal consequences are usually articulated, in the law-adjudication justificatory discourse, by other elements coming from the corresponding legal system that are easily identifiable or the belonging of which to the system and its importance are not controversial. It would be difficult for someone to deny that legal certainty is an aim protected by legal systems, leaving aside the issue that the expression "legal certainty" is a vague one which may have multiple meanings. In contrast, it is generally contentious whether the positive or negative effects of an unwritten social, economic or political principle or value can be used as a reason for adopting or rejecting a certain decision. Thus, e.g., it is not clear if "economic stability" can be brought forward in a decision as a reason for deciding one way or the other -and it is even less clear if judges are the ones entitled to do this balancing of values, principles and interests of a given society- despite the fact that it seems, at first glance, a positive and desirable status for a society to reach. Moreover, the analysis would be incomplete if one argues that economic stability is desirable, without mapping out whether there is some

${ }^{9}$ These examples are taken from the study of a set of rulings of the Spanish Constitutional Court. Following the order of the text, these rulings are: STC 54/2002, 27 ${ }^{\text {th }}$ February; STC $13 / 1992,6^{\text {th }}$ February; STC $155 / 2005,9^{\text {th }}$ June; ATC $135 / 2004,2^{\text {th }}$ April.; STC $22 / 1981,2^{\text {nd }}$ July. 
legal principle or legally-protected interest or good that is being defeated, unapplied or overruled by the desirable extra-legal effect that the decision may carry. In short, the problem of extra-legal consequences in judicial argumentation is that the justification of the desirability or positive character of them is not a straightforward issue. Further, in many cases this argument is dressed as one of common sense or authority which, at the end, hides both the existence of a fundamental disagreement on the matter and the reasons that really justify the decision (Bell, 1983, p. 36).

Secondly, the distinction is also useful to analyse the criteria for assessing the argument from consequences, to identify criteria that are problematic, especially when applied to extra-legal consequences, and to consider the need of proposing both common and differentiated criteria for each type of consequences. ${ }^{10}$ However, in some cases there is no clear dividing line between legal and extra-legal consequences, or the latter are redirected to legal principles or norms. Keeping in mind the concept of the argument referring consequences and the two types of consequences that play a role in legal argumentation, the following sections will expose the main points of consequence-based reasoning in the three authors under study: MacCormick, Wróblewski and Feteris.

\subsection{MacCormick's theory}

In MacCormick's theory, the argument from consequences acts as a second-order justification, which consists of the material justification of the normative and factual premises. This second-order justification follows the

\footnotetext{
${ }^{10}$ In my view, this is the proposal of Bengoetxea. Some of the common criteria for assessing consequences that he points out are the unity among the parts of the argument, the consistency or absence of contradictions among the elements of the argument, the coherence of the argument with the legal system, and the completeness, that is, that the argument gives account off all its premises. Concerning the different criteria, the parameters of evaluation of legal consequences are: substantive equality, the goals and purposes of the norm or branch of law, institutional values, constitutional principles or general principles of law. Extra-legal consequences, in turn, are assessed through axiological criteria such as economic stability, good international relations, protection of the social welfare of the society or of a certain group (1993b, p. 51) The problem is, precisely, that with the consequences being hypothetical, there is no possibility of an empirical evaluation when they are used as an argument; instead, their assessment is always made a priori and abstractly, which prevents the rational control of those hypotheses (Bengoetxea, 1993b, p. 46).
} 
deductive syllogism (first-order justification) when the latter is insufficient for solving a hard case or when there is a problem of interpretation, relevance, proof or classification. At this second level, three elements have an important role to play: consistency, coherence, and consequences of the alternative decisions. The first two are requirements of the decision making sense within the given system, while the latter looks for the decision to make sense with the perceptible world (MacCormick, 1997, p. 132).

MacCormick is especially interested in the justification of the second level because if the premises are well-justified, a formally correct deduction of the conclusion from the premises will lead to a justified or rational conclusion, interpretation, or decision. Consequences are brought into the theory as a reminder that legal decisions, and particularly judicial decisions, do not impact only the shape of the legal system, but also -and maybe mainly- directly on people and other dimensions or subsystems within society.

Following a suggestion of Rudden (1979), the Scottish scholar distinguishes between juridical and behavioural consequences. Juridical consequences, or consequences with logical implications relevant for legal justification, are those that have effects within the legal system. Behavioural consequences, on the other hand, are those effects that the decision produces in the world, in the behaviour of individuals and of economy and society (MacCormick, 1983).

There are other important aspects in MacCormick's writings about consequences. According to his view, some types and ranges of consequences are necessary and relevant in the justification of decisions. This is the result of placing his proposal as a middle-way between two extreme views: justification only based on consequences -with the main criterion here being the cost-benefit ratio- and justification that guarantees the nature and quality of the decision (MacCormick, 1995, pp. 101-102).

However, incorporation of consequences in judicial reasoning cannot ignore a crucial rule applicable to legal argumentation in general: that the legal answer "always has to be capable of being framed in terms of the law, through interpretation of statues or of precedents, or of legal principles developed through reflection on law as practically coherent normative order" (MacCormick, 2005, p. 101). In this vein, a primary requirement of legal reasoning is to show that the ruling "does not contradict validly estab- 
lished rules of law". A second requirement is to show that the decision is supported by established legal principles. When both requirements are not sufficient or conclusive in favour of a single ruling, then consistency and coherence need to be complemented by the argument about consequences (MacCormick, 2005, p. 104)

Together with the requirements of consistency and coherence, justification of legal reasoning should lead to the universalisation of the reasons involved in the decision, which is a way of realizing formal justice or the egalitarian character of the rule of law (MacCormick, 2005, pp. 230-231). The universalisation requirement ${ }^{11}$ applies also to consequentialist reasoning, which means that one criterion in the evaluation of the reasoning should be its capacity of being universalised, i.e. of becoming a general norm of the system. ${ }^{12}$ In the same sense, one should understand MacCormick's claim as saying that relevant consequences are those that are based on a general rule and not only on the specific effects produced by the decision over the parties (MacCormick, 1997, p. 150).

MacCormick identifies the determination of the criteria for assessing consequences as a "trap" of consequentialism. Without distinguishing among juridical and behavioural consequences, MacCormick says that this exam should be done in the light of criteria such as "justice", "common sense", "public policy", and "convenience” (MacCormick, 1997, p. 105; MacCormick, 1983, p. 255). Evaluation, then, considers a plurality of values that law aims to uphold, and not only utility or a cost-benefit ratio. This is why consequentialist argument cannot be strictly assimilated into utilitarian reasoning. Assessing consequences is not only done according to a plurality of values, but, in the words of this scholar, it is at least in

${ }^{11}$ By universalisation or universalisability in adjudication legal theorists refer to the fact that the judge that adopts a decision in a particular case has to be ready to give the same solution to all future cases with analogous relevant features. Uniformity in judicial decisions is a requirement also of consistency and coherence of the legal system, at the same time as being an expression of the rule of justice that "requires that those who are essentially similar should be treated alike" (Perelman, 1977, pp. 81-82; see also Perelman, 1964, p. 28). Perelman calls it the rule of formal justice, "because it does not tell us when beings are essentially similar nor how they must be treated".

${ }^{12}$ Universability is a feature of rationality of argumentation according to the great majority of theories of practical reasoning. Wróblewski says that even if it the former idea could be debated, universability can be nevertheless understood as a requirement of its legality (Wróblewski, 1984, pp. 160-161). 
part subjective, because different judges can attribute different weights or importance to the diverse evaluation criteria. He even raises the following question: can these criteria be redirected to a single metric or should one accept that they are incommensurable? This question, however, is left relatively unanswered. There are values, he argues, that are "imperfectly commensurable even situationally"; on the other hand, there are irresolvable contentious cases where the disagreement is a reasonable one (MacCormick 2005:117). The suggestion seems to be that in these last cases, judges can justify their rulings in several directions, and logical form, universability and completeness act as basic argumentative requirements that only guarantee a minimum of "correctness".

\subsection{Wróblewski's theory}

Firstly, it is advisable to note that Wróblewski uses the term "consequences" to describe two different operations: the "choice of consequences" and the "justification through consequences". The first use of the term refers to the competence that certain norms confer on judges for particularizing the consequences of their decisions, with this determination being inside their discretionary powers by explicit recognition of the legal order (Wróblewski, 1992, p.189). The typical example is criminal rules that enable judges to decide the years of imprisonment within an established range. However, the exercise of this competence does not necessarily involve consequencebased reasoning but rather is just the use of a judicial power.

Wróblewski's second use of the term "consequences" is the one of interest here. Justification through consequences, as Wróblewski explains, is justification that includes consequences among the reasons for justifying a decision or, in other words, a justification that justifies a decision or an action "by the evaluation of its consequences" (1984, p. 141). The author differentiates this type of justification from "justification through principles", which is a justification that has a principle as ultima ratio of the decision. Nonetheless, both types of justification are interrelated in three senses: first, because the classification of consequences is based on the category of principles; second, since "a justification through consequences is needed when the principles used in justification refer to consequences, or when the choice of these principles depends on the evaluation of their consequences" 
(Wróblewski, 1984, p. 156); and third, since they are likely to operate jointly, particularly in hard cases.Wróblewski classifies consequences in the categories of logico-semiotical, normative and factual (1984, p. 151). As has been said, the classification is related to three types of principles that he distinguishes: a) principles as a rule of justificatory reasoning (PRR), for example principles of logic, rhetoric, argumentation, topoi; b) an enacted norm and/ or its formal consequences or interpretative consequences treated as valid rules having some special relevance (PN); and c) a rule which is related with enacted norms but is neither their formal neither their interpretative consequence (PR). In this last case, the expression "principle" stands for the reasons of the norms, their rationalisation or their axiological grounds.

As to the first classification, logico-semiotical consequences are those inferred from the rules or decisions according to the rules of justificatory reasoning, that is, inferred from the first type of principle just mentioned (PRR). Formal consequences (i.e. those inferred from norms through formal logical calculi) and interpretative consequences (i.e. those that are the results of interpretation of enacted legal norms) are examples of this category. Normative consequences are of two types: a) logico-semiotical consequences considered to be valid rules according to an accepted concept of validity or rule of recognition; and b) consequences of rules or decisions in terms of rights or duties ascribed to subjects or that qualify their behaviour. Lastly, there are factual consequences of rules and decisions, which are identified and analysed on a socio-psychological empirical level of the phenomena and have a space-time dimension. This last type would be part of what I have called extra-legal consequences.

In his analysis, Wróblewski assumes "that the justification should include inter alia a reference to valid legal rules, to facts, and evaluations, and that the rules of reasoning and premises of the decision that are used could be controlled" (Wróblewski, 1984, p. 140). This assumption is a rather relevant one, since it presupposes several choices, e.g., the determination of the criteria of validity of legal rules and the decision of incorporating evaluations in processes of legal justification. It also reinforces the idea of making explicit in the decision several elements with the purpose of enabling its control. Choices, in turn, reveal theoretical options (e.g. how to understand the legal system) or even an ideology, in Wróblweski's words. His own theoretical framework for analysing justification contains choices 
and stands on two basic values: legality and rationality. Legality implies a decision according to law, i.e. that "a) the decision does not create the law, but applies it; b) the scope of law is determined, and c) the decision implements the axiology of applied law" (1984, pp. 158-159). Rationality refers to the formal conditions for the internal and external level of justification, which are consistency between the premises and the decision, consistency of the premises themselves and consistency between the premises and their justification. ${ }^{13}$

Wróblewski's proposal to evaluate consequences identifies internal, external and mixed criteria. The internal criterion evaluates consequences in relation to the elements of the system, and has as sub-criteria consistency, normative coherence and formal justice. Coherence requires that the argument, the chain of arguments and the decision resulting from it are axiologically coherent with the respective legal order (Wróblewski, 1984, p. 153), the verification of which demands the identification of the values underlying rules, principles and legal institutions. The external criterion uses values that enable the assessment of a legal decision from outside the system, substantive justice being the most important one. The mixed criterion is acceptability (Aarnio, 1987, p. 185), and consists of the approval or rejection of the consequences by a concrete audience, i.e., the one that has particular social features and shares a certain axiological consensus. The better- justified decision will be the one that achieves the adherence of the universal audience. Thus, the judge should ask himself if the consequences of his decision would be accepted or rejected by the parties and/or the public opinion. The acceptance of the decision depends on several factors, such as the amount of harmful consequences, any damages to goods, rights or interests that could be affected, and any unacceptable consequences (Wróblewski, 1984, p. 153).

\subsection{Pragma-dialectical theory}

The main purpose of the pragma-dialectical theory (van Eemeren and Grootendorst, 1992) applied to legal proceedings is to reconstruct the ar-

${ }^{13}$ Wróblewski $(1974,1984)$; in this last article the author distinguishes five levels of
justification. 
gumentation of the parties and of the judge as part of a critical discussion subjected to rational control (Feteris, 2005, p. 462). In several articles, Feteris applies and specifies the pragma-dialectical model to the analysis and evaluation of argumentation referring to consequences in legal decisions. For this author, argumentation referring to consequences is an argument that justifies a decision appealing to the consequences that adjusts to a desirable goal or that enable to reach that goal. That is, the positive or desirable consequences of an act are such to the extent they satisfy a desirable or valuable goal.

In its basic formulation, consequentialist argument is structured as follows:

point of view: Act $\mathrm{X}$ is desirable

because: Act $\mathrm{X}$ produces consequence $\mathrm{Y}$ (empirical statement)

and: $\quad$ Consequence $\mathrm{Y}$ is desirable (normative statement)

The point of view refers to a certain act $X$ that can be a decision or an interpretation. The normative statement establishes that consequence $\mathrm{Y}$ is desirable, and the empirical statement holds that act $\mathrm{X}$ produces consequence $Y$. The important thing is to answer affirmatively the two critical questions that guide the evaluation of pragmatic argumentation: "Does application of rule $\mathrm{X}$ in interpretation X' lead to consequence Y?" 14; "Is consequence $\mathrm{Y}$ indeed (un)desirable?”. The first question is concerned with the existence of a causal relation between the act and the consequences, and evaluates the empirical statement; the second one asks for the justification of the normative statement, or in other words, for the reasons that support the statement affirming the desirability or acceptability of the consequences at stake.

It is in the subordinated level where these questions should be solved, the second one by demonstrating the compatibility of consequences Y' with

${ }^{14}$ In a similar line of argument, Van Eemeren and Grootendorst point out that with instrumental argumentation, as a model of argumentation based on causality relation, the important questions are: "Is the announced effect of the proposed measure really so desirable? Will this effect indeed follow? Or could it be achieved more easily by way of another measure? Does the proposed measure not have any serious negative side-effects?"; van Eemeren and Grootendorst (1992, p. 102). 
a purpose $\mathrm{P}$ and justifying purpose $\mathrm{P}$ as intended by the historical legislator (e.g., through the study of parliamentary debate), or as objectively prescribed by the legal order (e.g., explaining to what extent purpose $\mathrm{P}$ underlies certain rules, principles or values) (Feteris 2005).

However, these justifications are neither simple nor plain. Identification of the purpose intended by the historical legislator does not necessarily work when interpreting textural norms, such as constitutional clauses, because their vagueness was probably needed to reach an agreement that would enable different readings of them. In this sense, it would be difficult to identify "the" purpose of the historical legislator. In addition, it is frequently the case that the purpose of the legislator when enacting a norm can collide with other ends protected by different valid legal rules. Additionally, the purpose of a norm is not always clear, explicit or easy to detect. In the case of identifying the "purpose objectively prescribed by the legal order”, similar problems arise.

As to the first critical question noted above, there is no further orientation of the elements that would help to answer it, because it refers to the causal relation between a decision or an act and the projected consequences, which is a factual problem relatively unsolved when arguing about possible future consequences.

Starting from the simple structure of consequentialist argument, Feteris proposes a pragma-dialectical framework for analysing and evaluating practical arguments in Law. The argument referring consequences on its own may be weak or insufficient, and it can be complemented redirecting the desirability of consequences $\mathrm{Y}$ of act $\mathrm{X}$ to the desirability of the end $\mathrm{Z}$. This complex argumentation is constructed in three levels -main, subordinated and sub-subordinated-, and each level can adopt both positive and negative signs. The structure is represented as follows: ${ }^{15}$

1. Interpretation $\mathrm{X}$ is desirable; interpretation $\mathrm{X}$ leads to $\mathrm{Y}$; $\mathrm{T}$ is desirable (consequentialist argument)

2. $\mathrm{Y}$ is desirable; $\mathrm{Y}$ satisfies principle, goal, directive or value $\mathrm{Z}$; $\mathrm{Z}$ is desirable (teleological argument)

3. $\mathrm{Z}$ is desirable; $\mathrm{Z}$ is coherent and consistent with general legal principles,

${ }^{15}$ Feteris (2002b, p. 111). 
ends and values P underlying the legal system (argument from coherence or consistency)

As can be appreciated, this is not a simple model of consequentialist reasoning, but the coordination of three arguments - consequentialist argument, teleological argument and argument from coherence- provides a structure with more force than the sum of the individual argumentative weights. This type of justification is used when the judge is confronted with different possibilities of interpretation. In these cases, judicial argumentation should reflect the choice between the two rival points of views of the parties, and should show the balancing of these positions according to the desirable or undesirable consequences for the end of the rule. ${ }^{16}$

Feteris also emphasises the importance of reasonableness and equity as values for the judge to consider when balancing different competing interpretations of a rule, and that may be used in restricting or extending the sphere of application of a rule based on the absurd consequences that a too extensive or too restrictive application can produce with relation to the rule's goal (Feteris, 2005, p. 462).

In the pragma-dialectical model, as it has been shown, the determination of the goal or purpose of the norm applicable to the case plays a central role. However, legal systems contain a multiplicity of goals that can easily collide in a concrete case, so the decision to favour one and to leave aside the other should be also justified. A further problem could be those cases in which there are no explicit norms to adjudicate the case. In such cases, the solution, according to this model, would be to recall the goals that inspire the legal order as a whole, even when they are not explicit ones. This type of technique has the known problems of "detecting" or "reading" the values that underlie a certain legal order, or else the problems of "assigning" meanings which implies several interpretative choices or definitions, with the result that the exercise of detection, reading or ascription of meaning can widely vary among different interpreters. A related point has to

16 "If application of rule $R$ in interpretation $X 1$ in the circumstances of the given case $C 1, C 2, \ldots C n$ leads to $Y 1$, and $Y 1$ is desirable, and if application of rule $R$ in interpretation $X 2$ leads to $Y 2$ and $Y 2$ is undesirable, then application of rule $R$ in interpretation $R 1$ is to be preferred to application of rule $R$ in interpretation $X 2$ " (Feteris, 2008, p. 490). 
do with the argument referring to extra-legal consequences. Feteris' model does not differentiate among legal and extra-legal consequences, since the important point is that consequences are linked with the goal or purpose of the norm or of the legal order. In this regard, extra-legal consequences that cannot be easily related to a clear purpose of a norm or of the legal order would not fit in the proposed structure.

In this section, starting from an outline of the argument from consequences, I have briefly explained the main points of the theory of each scholar as to this type of argument. From the above description, some similarities and differences emerge, which are interesting to highlight for the purpose of the following section. With regard to the similarities, all three scholars insist in one way or another that the decision, and therefore, the arguments from consequences that support it, has to respect the rule of law and the valid law of the legal system. Secondly, all three are concerned with the need of establishing criteria for evaluating the use of the argument from consequences. While MacCormick proposes general criteria and Wróblewski classifies consequences in three types, Feteris points out the critical question in terms of the desirability of the possible consequences to which a certain decision could lead, even though she does not offer criteria for assessing them. Third, both MacCormick and Wróblewski make a distinction similar to the one given here between legal consequences -juridical and normative- and extra legal consequences - behavioural and factual. Finally, these same two authors consider that, in some cases, the use of the argument of extra legal consequences or the influence of no-law, to borrow Wróblewski's expression, is inevitable or it is a necessary condition for the rationality of the decision.

There are also divergent points among the proposals under analysis that come from the different ways of approaching consequentialist argumentation. MacCormick's normative view consists of including the argument from consequences in the wider picture of the two levels of justification and the requirement that the decision has to make sense both within the legal system and with the world. Wróblewski assumes an analytic style in treating this argument, since he distinguishes and classifies both the types of consequences relevant to the Law and the criteria for evaluation. Feteris, in turn, is mainly concerned with the structure of the argument 
from consequences or with how the different levels of argumentation are interconnected.

\section{Judges on consequences}

This section will offer a synthesis of the main consequentialist arguments -both legal and extra-legal- given in a recent ruling of the Chilean Constitutional Court, ${ }^{17}$ and will analyse them in the light of the theoretical proposals described in the previous section, pointing out the arguments' strengths and weaknesses.

The ruling chosen is one that declared unconstitutional an article of a statute that regulates the Previsional Health Institutions (PHI or "Isapres"). ${ }^{18}$ The section that was challenged through this legal proceeding regulated the faculty of the public institution that supervises the $\mathrm{PHI}(\mathrm{Su}-$ perintendence) in fixing ranges for differentiating prices of the health insurance plans according to the age and gender of the insured (significantly more expensive for people of 60 or more years and for women of 20 years onwards). The Court considered this norm against the constitutional principles of equality, protection of health and protection of social security (art.19 $\mathrm{n}^{\mathrm{O}} 2,9$ and 18 of the Constitution).

I will basically sum up the lines of consequentialist arguments that were presented in these proceedings by dividing them into two groups: legal and extra-legal consequences. On the one side, the ruling points out five cases where the declaration of unconstitutionality should be avoided for its negative or undesirable legal consequences. Thus, unconstitutionality should be avoided if: a) it leads to a normative gap; b) it produces legal uncertainty; c) it results in a more harmful situation than that pre-existent to the declaration of unconstitutionality (horror vacui); d) it is inconvenient for public interest or for the rule of law; or e) it produces interference in the legislative sphere.

${ }^{17}$ STC 1710-10-INC, 6th August 2010.

${ }^{18}$ The Chilean Health Systems combines, since 1981 reform, a public (National Health Fund or "Fonasa") and a private system. Currently, 22\% of the Chilean population has private health insurance (2011). The datum is from INE-CEPAL CHILE: Proyecciones y Estimaciones. 
On the other side, in the proceedings, arguments were given in order to demonstrate the possible negative extra-legal effects that the declaration of unconstitutionality could produce. Such a declaration could: a) have negative effects on the contributors, such as a change in the coverage, benefits and price for their health insurance plans; b) endanger the existence of the private health system; and c) have deep negative economic repercussions in the public budget for Health, since the increase in the private insurance plans would generate a migration of people from the private to the public system. ${ }^{19}$ However, despite these arguments-which are, at least in appearance, strong-to reject the petition of unconstitutionality of the challenged statute, the decision of the majority supported the declaration of unconstitutionality.

The analysis and evaluation of these arguments can be done using the different elements and tools reviewed in the former section. Legal consequences, as it has been already suggested, are less problematic than extralegal consequences since the former are linked with elements of the legal system, the existence of which is uncontroversial. In this sense, legal consequences such as avoiding legal gaps or ensuring legal certainty, from the perspective of the three theories above, cannot be understood in an isolated way but only in relation to other legal arguments such as the teleological argument and the argument from coherence. For example, the claim that the declaration of unconstitutionality would not be coherent with the rule of law could be understood as a mixed argumentation composed of consequentialist and coherence arguments.

On the other hand, the argument referring to extra-legal consequences appears as an expression of MacCormick's requirement that the decision should make sense with the world, viewing "making sense" as taking into account the decision's different effects in the extra-legal reality, such as the possible economic impact of declaring the statute unconstitutional. This economic impact could affect the beneficiaries of private health insurance, the State, and the private health system. Here, nevertheless, the questions of how to select who, within the different persons, groups or institutions that can be affected by these consequences, should be taken into account in

19 The latter is argued in the presentations of the governmental health institutions. These possible future consequences were backed by statistical data in the Report "Elimination of the Factors' Board”, of the Superintendence of Health ( $30^{\text {th }}$ May 2010). 
the reasoning of the judge and the question of how to balance positive and negative consequences among those affected by a decision remains unanswered by the proposals of the scholars under study, even when those questions seem to contain decisive elements in the evaluation of the argument referring to extra-legal consequences.

Following MacCormick's proposal, the evaluation of consequences should be done through criteria such as substantive justice, public convenience and common sense. However, these criteria are insufficiently defined or, in other words, are soft directives for balancing positive and negative consequences of the alternative decisions, since they are based on contested concepts that need, in turn, to be defined or delimited before being used as a parameter for the soundness or correctness of consequentialist arguments. For example, in the case under analysis, could it be said that the changes in coverage, benefits and price of the health insurance plans are unfavourable consequences of the declaration of unconstitutionality? And, is the correctness of this conclusion corroborated by the fact that those effects are against substantive justice? A similar problem arises with Wróblewski's criterion of acceptability: When should one conclude that the argument from consequences has complied with this criterion? Which is the particular audience that has to potentially accept the argument from consequences? In light of the extra-legal consequences of this proceeding, it is difficult to imagine to what extent a reference to the probability of being accepted by a social group or by the universal audience contributes to the soundness of an argument.

An additional problem is that these criteria are, on the one hand, multiple and there is uncertainty whether there is any order for applying them or if one of them alone is enough for assuring the proper construction of the argument from consequences. Moreover, if the solution that results from applying one criterion, e.g. substantive justice, is contrary to the solution that results from applying a different criterion, e.g. public interest or common sense, there are no meta-criteria that resolve the contradiction. On the other hand, these criteria do not account for the peculiarities and problems associated with each type of consequences.

A further issue in evaluating the argument referring consequences is the test of universalisation, that is, to respond positively to the question "is it possible to use this same consequentialist argument in future similar 
cases and in this way, allow the decision to become a general norm of the system?". This test could be, nevertheless, problematic in the case of extralegal consequences, because they are tightly interlinked with the particularities of the case. Additionally, in practice, in cases of abstract control of constitutionality as the one under study, the possibility of universalising the reasons would take place only when the challenged norm is the same one.

It is not necessary, in Wróblewski's vision, in apparent contrast to Feteris' proposal, to justify the introduction of extra-legal consequences as a factor in argumentation by trying to link them, sometimes in a forced way, with a certain norm or with values or purposes supposedly pursued by the legal order as a whole; instead, one should try to relate the argument to reliable data that supports the prediction of (un)favourable future consequences of the decision.

Feteris' pragma-dialectical approach makes explicit the different statements that are needed for producing a sound decision, including using justified premises and connecting and organising them in levels (main, subordinated, sub- subordinated). This approach properly points out the critical questions concerning the external justification of the empirical and normative statements, though it does not discuss in depth in how to achieve this. In the Chilean case study given above, the first critical question would be "does the unconstitutionality of the challenged statute leads to a legal gap?" It would then be necessary to rewrite this question with each of the effects alleged. The second critical question would be "is Y undesirable?", replacing Y with each of those effects (legal gaps, legal uncertainty, increase of the insurance plans, etc.) If the critical questions remain unanswered, or if it is detected that the attribution of (un)desirability of a possible consequence of a decision is unjustified, then the argument looses soundness and lacks force as a justificatory reason for the decision.

Applying the complex pragma-dialectical framework, which combines the argument from consequences, the teleological argument and the argument from coherence, to one of the arguments of the Chilean proceedings, one can reconstruct the framework as follows:

1. The declaration of unconstitutionality of the norm is undesirable; the declaration of unconstitutionality and the derogation of the norm generate a legal gap; this legal gap is undesirable. 
2. This legal gap is undesirable; this legal gap violates the right to equality and leaves privately-insured people unprotected from PHI; violation of equality and leaving privately-insured people unprotected is undesirable.

3. Violation of equality and leaving privately-insured people unprotected is undesirable; violation of equality and leaving privately-insured people unprotected is incoherent with the legal system that grants equality and legal certainty as general principles of law.

According to this model, it is possible to say that the undesirability of producing a legal gap is linked with the violation of certain goals of the legal system, such as equality, and to the goal of the norm that regulates PHI, which is to protect the people affiliated to those health institutions. Nevertheless, a different interpretation is perfectly possible, considering other norms of the system and balancing diverse goals, which means that the selection of the goal has to also be justified, preventing reasonable counterarguments.

Lastly, in these proceedings the arguments referring to extra-legal consequences are supported by empirical data, an element that is absent from the theoretical proposals. ${ }^{20}$ For example, data are used by some parties to make a prospective picture of what the behaviour of privately-insured people would be if insurance plans increase their prices; there is also a calculation of the amount of money that the migration of the privately-insured to the public health system would cost the state. For this purpose, legal argumentation theory could bring in some of the methods and tools proposed by empirical jurisprudence and economic analysis of law; judicial practice could consider establishing mechanisms similar to those divisions that parliaments have for analysing the financial impact of legislation, so that higher and constitutional courts could evaluate the future economic effects of their rulings and that this information could be used as an argument in the decision.

${ }^{20}$ With the consequences being hypothetical, there is no possibility of an empirical evaluation when those consequences are used as an argument, but their assessment is always made a priori and abstractly; empirical data, then, is only useful to give force to the claim to favourable or unfavourable future consequences by comparing with analogous past situation or attempting to predict the magnitude of the impact. 
In this section, I have applied three theoretical models to some consequentialist arguments that were put forward both by the court and the parties to the proceedings, and this has permitted me to identify some strong and weak points in each model. To sum them up, the strength of MacCormick's theory lies in distinguishing types of consequences and being concerned with its problems and evaluation; the weak point refers mainly to the vagueness of the criteria for assessing consequences and the absence of specific elements for evaluating the argument from extra-legal consequences. Wróblewski's proposal of distinguishing types of criteria for evaluating consequences is useful because it includes different dimensions that can operate jointly; the problem is one of imprecision of the criteria of evaluation, as with MacCormick's theory, and the lack of a link between the types of consequences and the classification of criteria. Finally, Feteris' model has the strength of making visible the several argumentative steps to obtain a well-supported decision and of singling out the importance of the critical questions, though it fails to give criteria for evaluating consequences and purports to establish a strong link between argument referring consequences and goals of the legal system, which is doubtful at least with respect to extra-legal consequences.

\section{Conclusions}

In this paper, I have examined three theoretical proposals concerning the argument referring consequences and tried to show, with an example, to what extent they are helpful and sufficient for analysing and evaluating the use of this argument in judicial decisions.

The three proposals subscribe, in my view, to the original goal of argumentation theories: subjecting judicial decisions to criteria of rationality that constitutes a limit to judicial discretion. However, a way of enhancing the practical use of the argument referring consequences would be to integrate elements of the three theories. The idea of universalising the reasons for making a decision, the identification of formal and substantive criteria for its evaluation and a well-defined structure are features that contribute to a better framing and justification of the inclusion of the future possible consequences of a decision in judicial reasoning. Furthermore, the distinc- 
tion between legal and extra-legal consequences is necessary because the latter are likely to produce more tensions than the former, especially if they are used to hide the judicial reading-in of political, economic and social considerations in cases of legal gaps or in the interpretation of open-texture legal norms. This may lead, therefore, to the need of increasing the standards of justification when extra-legal consequences arguments are at stake.

As to evaluation of the argument from consequences, concrete guidelines and a more accurate definition of the criteria should be given, so that they could stand as useful parameters to control the argument's soundness and correctness. On the other hand, empirical tools should be incorporated to evaluate extra-legal consequences argumentation. These last two suggestions could be the guiding questions of a future research.

\section{Works Cited}

Aarnio, A. The Rational as Reasonable. A Treatise on Legal Justification. Dordrecht: Kluwer, 1987.

Bell, J. Policy Arguments in Judicial Decisions. Oxford: Clarendon, 1983.

Bengoetxea, J. "Una defensa del consecuencialismo en el Derecho." Telos (Revista latinoamericana de estudios utilitaristas) II (2) (1993b): 31-68.

Dworkin, R. Law's Empire. Cambridge: Harvard University Press, 1986.

Eemeren, F.H. van and R. Grootendorst. Argumentation, Communication and Fallacies. A Pragma-Dialectical Perspective. Hillsdale N.J.: Lawrence Erlbaum, 1992.

Feteris, E. "A Pragma-Dialectical Approach of the Analysis and Evaluation of Pragmatic Argumentation in a Legal Context." Argumentation 16 (2002a): 349-367.

Feteris, E. "The Rational Reconstruction of Argumentation Referring to Consequences and Purposes in the Application of Legal Rules: A Pragma-Dialectical Perspective." Argumentation 19 (2005): 459-470.

Feteris, E. "The Rational Reconstruction of Weighing and Balancing on the Basis of Teleological-Evaluative Considerations in the Justification of Judicial Decisions." Ratio Juris 21(4) (2008): 481-495.

Feteris, E. "The Role of Arguments from Consequences in Practical Argumentation in a Legal Context." In Hansen, H. et al., Argumentation and its Applications, Ontario Society for the Study of Argumentation (CD-rom) (2002b)

García Amado, J.A. "Del método jurídico a las teorías de la argumentación." Anuario de Filosofía del Derecho III (1986): 151-182. 
MacCormick, N. "On Legal Decisions and their Consequences: From Dewey to Dworkin.” New York University Law Review 58 (2) (1983): 239-258.

MacCormick, N. Legal reasoning and legal theory. Oxford: Clarendon, 1997.

MacCormick, N. Rhetoric and the Rule of Law. Oxford: Oxford University Press, 2005.

Perelman, Ch. De la Justicia. México: Universidad Nacional Autónoma de México, 1964.

Perelman, Ch. The Idea of Justice and the Problem of Argument. London: Routledge \& Kegan Paul, 1977.

Perelman, Ch. \& L. Olbrechts-Tyteca. Tratado de la argumentación. La nueva retórica. Madrid: Gredos, 2000.

Scheffler, S. (ed.). Consequentialism and its Critics. Oxford: Oxford University Press, 1988.

Sinnot-Armstrong, W. "Consequentialism”. Stanford Encyclopedia of Philosophy, online: http://plato.stanford.edu/entries/consequentialism/, 2006.

Slote, M. “Consequentialism”. Encyclopedia of Ethics (pp. 211-214). New York \& London: Garland, 1992.

Walton, D. "Historical Origins of Argumentum ad Consequentiam." Argumentation 13 (1999): 251-264.

Wróblewski, J. "Justification through principles and justification through consequences." In Farrali, C. and Pattaro, E., Reason in Law (pp. 129-161). Milano: Giuffrè, 1984.

Wróblewski, J. The Judicial Application of the Law. Dodrecht: Kluwer, 1992. 